\title{
SUB-ÅNGSTROM TRANSMISSION ELECTRON MICROSCOPY AT 300keV
}

M.A. O'Keefe*, E.C. Nelson*, J.H. Turner* and A. Thust ${ }^{\circ}$

*National Center for Electron Microscopy, LBNL B72, Berkeley, CA 94720, USA

${ }^{\circ}$ Institut für Festkörperforschung, Forschungszentrum Jülich GmbH, D-52425 Jülich, Germany

DISCLAIMER

This document was prepared as an account of work sponsored by the United States Government. While this document is believed to contain correct information, neither the United States Government nor any agency thereof, nor The Regents of the University of California, nor any of their employees, makes any warranty, express or implied, or assumes any legal responsibility for the accuracy, completeness, or usefulness of any information, apparatus, product, or process disclosed, or represents that its use would not infringe privately owned rights. Reference herein to any specific commercial product, process, or service by its trade name, trademark, manufacturer, or otherwise, does not necessarily constitute or imply its endorsement, recommendation, or favoring by the United States Government or any agency thereof, or The Regents of the University of California. The views and opinions of authors expressed herein do not necessarily state or reflect those of the United States Government or any agency thereof, or The Regents of the University of California.

Ernest Orlando Lawrence Berkeley National Laboratory is an equal opportunity employer.

Ernest Orlando Lawrence Berkeley National Laboratory - LBNL-47531 


\title{
SUB-ÅNGSTROM TRANSMISSION ELECTRON MICROSCOPY AT 300keV
}

\author{
M.A. O'Keefe*, E.C. Nelson*, J.H. Turner* and A. Thust ${ }^{\circ}$ \\ *National Center for Electron Microscopy, LBNL B72, Berkeley, CA 94720, USA \\ ${ }^{\circ}$ Institut für Festkörperforschung, Forschungszentrum Jülich GmbH, D-52425 Jülich, Germany
}

Sub-Ångstrom TEM to a resolution of $0.78 \AA$ has been demonstrated by the one-Ångstrom microscope (OÅM) project at the National Center for Electron Microscopy. The OAM combines a modified CM300FEG-UT with computer software ${ }^{1,2}$ able to generate sub-Ångstrom images from experimental image series.

Sub-Ångstrom HREM is gaining in importance as researchers design and build artificially-structured nanomaterials such as semiconductor devices, ceramic coatings, and nanomachines. Commonly, such nanostructures include atoms with bond lengths shorter in projection than the point resolution of a mid-voltage $\mathrm{HREM}^{3}$. In addition, image simulations have shown that structure determinations of defects such as dislocation cores require sub-Ângstrom resolution ${ }^{4}$, as will hold true for grain boundaries and other interfaces.

Sub-Ångstrom microscopy with a transmission electron microscope requires meticulous attention to detail. As resolution is improved, resolution-limiting parameters need to be reduced. In particular, aberrations must be minimized, power supplies must be stabilized, and the microscope environment optimized to reduce acoustic and electromagnetic noise in addition to vibration. Figure 1 shows limits for several important parameters. To reach a direct resolution of $d_{S}$ the spherical aberration coefficient $C_{S}$ needs to be below $6 d_{S}{ }^{4} / \lambda^{3}$. Thus, to reach $0.8 \AA$ at $300 \mathrm{keV}$ (fig. 1 ), $\mathrm{C}_{S}$ should be less than $0.03 \mathrm{~mm}\left(0.02 \mathrm{~mm}\right.$ would be optimum ${ }^{5}$ ). Alternatively, to reach an information limit of $\mathrm{d}_{\Delta}$ by focal reconstruction requires the standard deviation of focus spread $\Delta$ to be less than $2 \mathrm{~d}_{\Delta}^{2} /(\pi \lambda)$, or $21 \AA$ at $300 \mathrm{keV}$ for $\mathrm{d}_{\Delta}=0.8 \AA$. Two- and three-fold astigmatism, $\mathrm{A}_{1}$ and $A_{2}$ must be kept low. To ensure phase distortions of less than $\pi / 4$ at resolutions of $d_{A_{1}}$ and $d_{A_{2}}, A_{1}$ and $A_{2}$ must be below $\mathrm{d}_{\mathrm{A}_{1}}{ }^{2} /(4 \lambda)$ and $3 \mathrm{~d}_{\mathrm{A}_{2}}{ }^{3 /\left(8 \lambda^{2}\right)}$ respectively, or $8 \AA$ and $500 \AA$ to reach $0.8 \AA$ at $300 \mathrm{keV}$. Even specimen thickness must be reduced ${ }^{6}$ to less than $2 \mathrm{~d}_{\mathrm{s}} 2 / \lambda$, requiring less than $65 \AA$ to reach $0.8 \AA$ at $300 \mathrm{keV}$.

Sub-Ångstrom resolution was achieved with the OAM by placing the TEM in a favorable environment ${ }^{7}$, and by reducing its three-fold astigmatism $\mathrm{A}_{2}$, and information limit $\mathrm{d}_{\Delta}$. Before correction, $\mathrm{A}_{2}$ was measured as $2.46 \mu \mathrm{m}$ (fig.2a); after correction, as $300 \AA$ (fig.2b), corresponding to $0.68 \AA$ at a $\pi / 4$ phase limit. Measurement of the energy spread (gun spread plus high-voltage ripple) as $0.93 \mathrm{eV} \mathrm{FWHH}$ indicated a focus spread $\Delta$ of $20 \AA$ and an information limit of $0.78 \AA$ (fig.1). Tests with a diamond specimen showed that $\mathrm{A}_{2}$ was corrected and the OÅM could successfully resolve the $0.89 \AA$ (400) dumbbell spacings in [110] diamond. ${ }^{3,8,9}$

Sub-Ångstrom resolution is improved by lowering the TEM information limit. Measurements showed that the expected limit could be lowered below $0.75 \AA$ by reducing the gun extraction voltage (fig.3). As a test, we have imaged the $0.78 \AA$ (444) dumbbell spacings in [112] silicon. The 444 reflections have optimum transfer into the image at an alpha-null defocus ${ }^{10}$ of $-3783 \AA$ (fig.4). Operating with reduced illumination at $3 \mathrm{kV}$ extraction voltage, we obtained focal series of images that produced diffractogram spots out to $0.78 \AA$ (fig.5). In $10 \AA$-step focal series, the $0.78 \AA$ (444) spots showed the expected Fourier period ${ }^{11}$ of $62 \AA$, reaching maximum intensity every 60 to $70 \AA$ as predicted (fig.4), indicating linear transfer from the specimen.

Sub-Ångstrom spacings of $0.78 \AA$ appear in our focal series. At the extreme limit of the microscope's performance, images are noisy, but $0.78 \AA$ dumbbells appear at both "white-atom" and "black-atom" defocus, indicating linear transfer of the $0.78 \AA$ spacing from the specimen. A distinct pair of "white atoms" is clearly seen in the top left of fig.6a. "Black-atom" separation is best revealed when the image is profiled (fig.6b). ${ }^{12}$

1. W.M.J. Coene, A. Thust, M. Op de Beeck and D. Van Dyck, Ultramicroscopy 64 (1996) 109-135.

2. A. Thust, W.M.J. Coene, M. Op de Beeck and D. Van Dyck, Ultramicroscopy 64 (1996) 211-230.

3. Y.C. Wang et al., 57th Ann. Proc. MSA, Portland, Oregon (1999) 822-823.

4. C. Kisielowski et al., in 58th Ann. Proc. MSA, Philadelphia, Pennsylvania (2000) 16-17.

5. Michael A. O'Keefe, in 58th Ann. Proc. MSA, Philadelphia, Pennsylvania (2000) 1036-1037.

6. Michael A. O'Keefe, in 55th Ann. Proc. MSA, Cleveland, Ohio (1997) 1165-1166.

7. John H. Turner, Michael A. O'Keefe \& Robert Mueller, 55th Ann. Proc. MSA, Cleveland, Ohio (1997) $1177-1178$.

8. Michael A. O'Keefe, in 58th Ann. Proc. MSA, Philadelphia, Pennsylvania (2000) 1192-1193.

9. Michael A. O'Keefe et al., Ultramicroscopy (2001) submitted.

10. Michael A. O'Keefe, these proceedings.

11. Sumio Iijima and Michael A. O'Keefe, J. Micros. 117 (1979) 347-354.

12. Work supported by the Director, Office of Science -- through the Office of Basic Energy Sciences, Material Sciences Division, of the U.S. Department of Energy, under contract No. DE-AC03-76SF00098. 


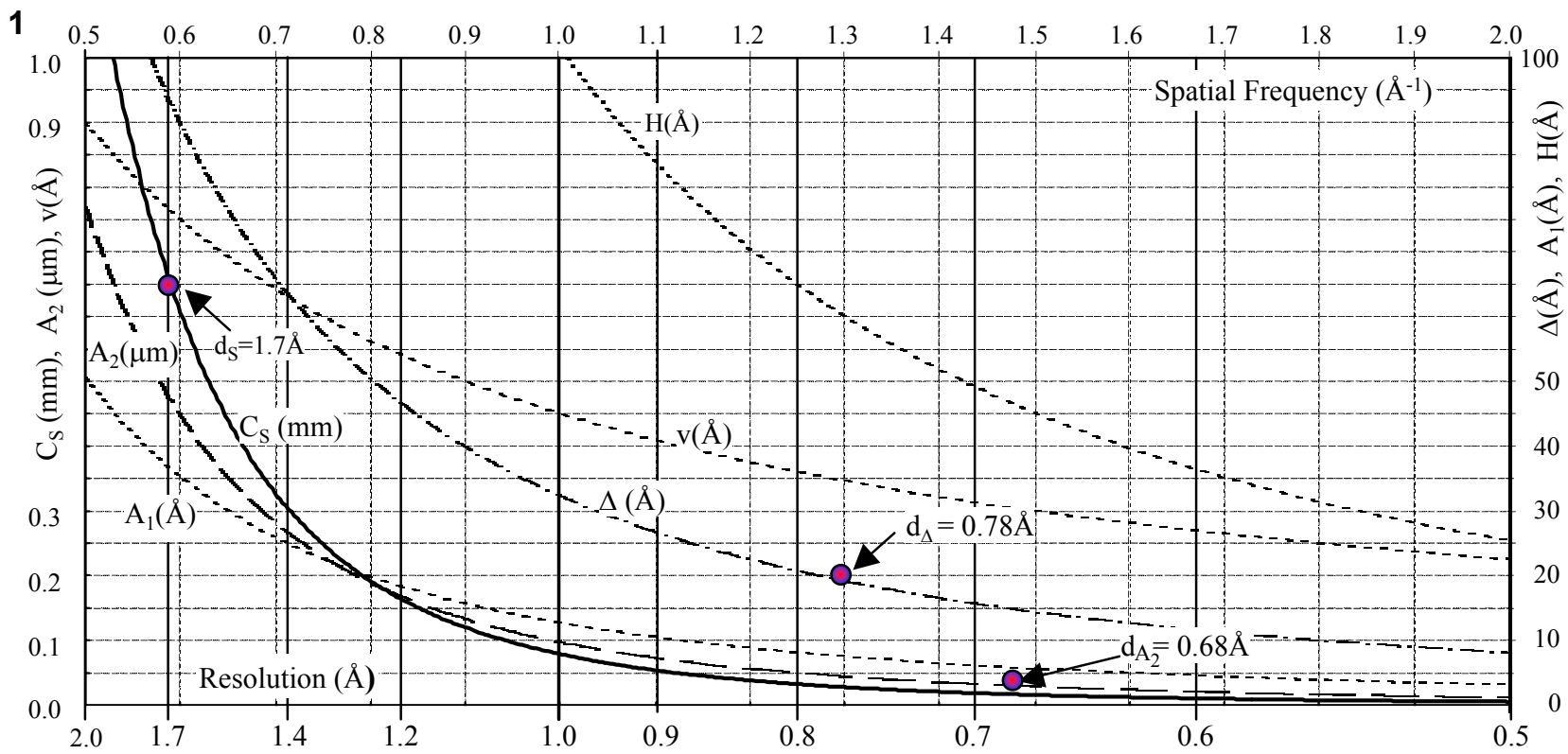

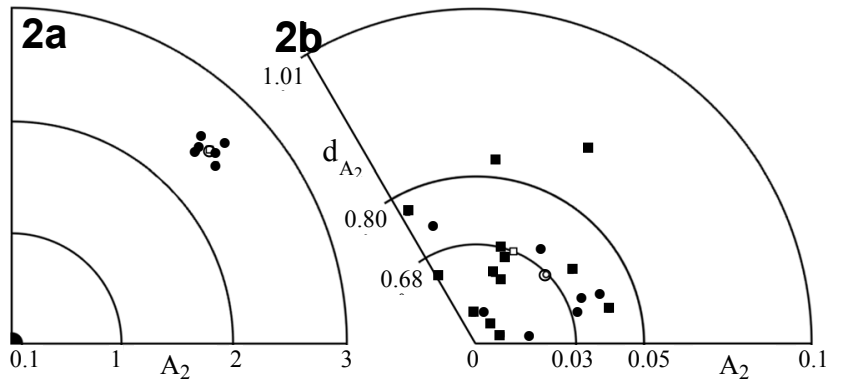

Fig.2. Measured 3-fold astigmatism before (a) and after (b) correction. Mean values are hollow. Mean in (a) is $2.46 \mu \mathrm{m}$. Means in (b) are $0.03 \mu \mathrm{m}$, corresponding to $\pi / 4$ at $0.68 \AA$.

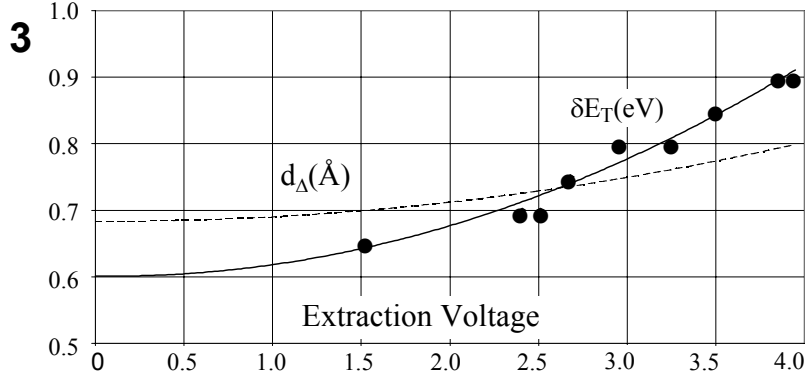

Fig.3. As extraction voltage is reduced from $4.0 \mathrm{keV}$, measured FWHH energy spread $\delta \mathrm{E}_{\mathrm{T}}(\mathrm{eV})$ falls from $0.93 \mathrm{eV}$, and information limit $\mathrm{d}_{\Delta}(\AA)$ falls from $0.8 \AA$.

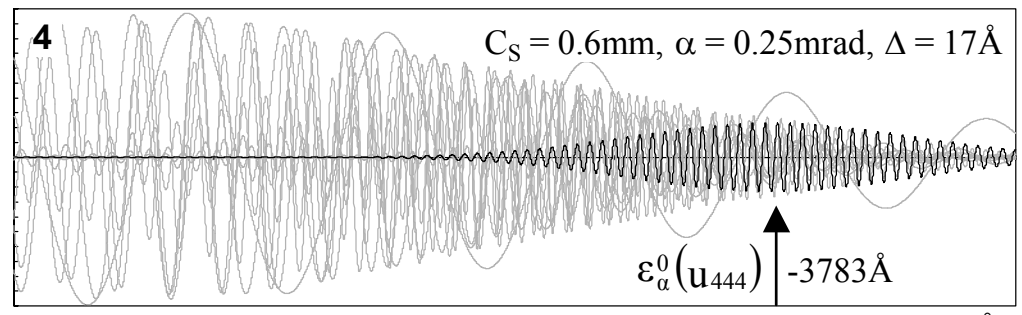

Fig.4. Plot of beam phases shows position of $\alpha$-null defocus for $0.78 \AA \AA$.
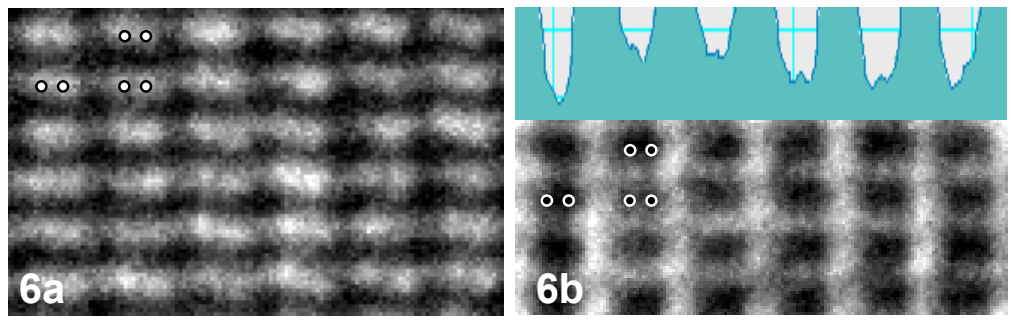

Fig.6. Images of $\mathrm{Si}[112]$ show separation of $0.78 \AA \mathrm{Si}-\mathrm{Si}$ dumbbells. (a) "white-atom" image. (b) "black-atom" dumbbell is difficult to see, but profile (averaged vertically over 6 dumbbells) shows separation.

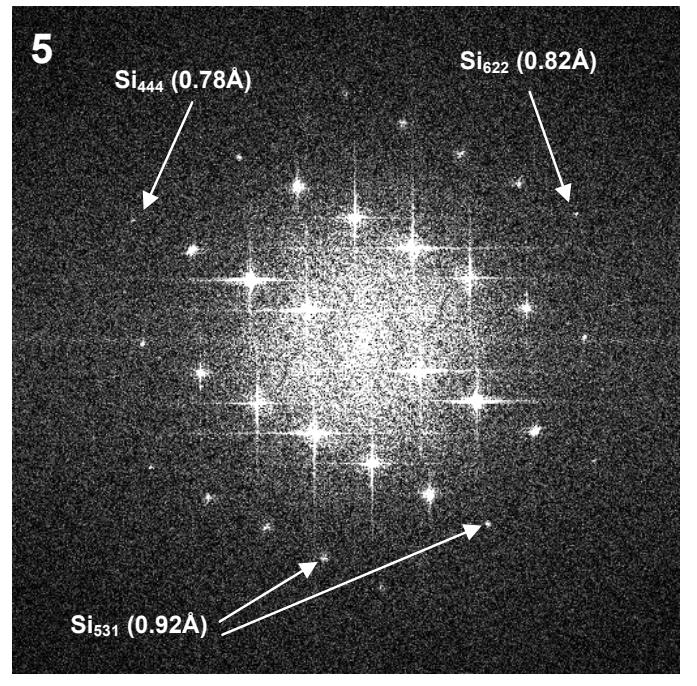

Fig.5 Diffractogram from $\mathrm{Si}[112]$ image has intensities that exhibit linear-transfer Fourierdefocus behavior down to $0.78 \AA$. 